\title{
Enteral glutamine supplementation in critically ill patients
}

\author{
Xu Tian ${ }^{1}$ and Guo-Min Song ${ }^{2^{*}}$ \\ See related research by van Zanten et al., http://www.ccforum.com/content/19/1/294
}

In Critical Care recently, we read with great interest the systematic review and meta-analysis by van Zanten and colleagues, who compared enteral glutamine with control in critically ill patients in terms of clinical outcomes [1]. We enthusiastically congratulate and applaud them for their groundbreaking work on this topic. However, some issues in their study should be noted and further discussed. Firstly, a predefined subgroup analysis was adopted through excluding the randomized controlled trials (RCTs) done by van Zanten and colleagues, in which other supplemental nutrients were used [2]. To test the robustness of overall effects, these authors performed this sensitivity analysis appropriately. However, a sensitivity analysis was not performed in all subgroup analyses. Although subgroup analysis is one of the methods of sensitivity analysis, it should be carried out in order to further test the influence of an individual study on the overall results [3]. Secondly, the variations of each mean difference reported in all eligible RCTs are so obvious in terms of intensive care unit length of stay and thus a standardized mean difference (SMD) effect size rather than weighted mean difference should be selected to measure the pooled result, even though SMD does not resonate well with most clinicians [3]. Thirdly, these authors stated that "a unique feature of this metaanalysis is that no language restrictions are placed on the searches" [1]. However, it should be noted that only EMBASE, MEDLINE, CINAHL (Cumulative Index to Nursing and Allied Health Literature), Cochrane Central Register of Controlled Trials, and the Cochrane Database of Systematic Reviews were searched. Other databases such as the Chinese Biomedical Literature Database and the Chinese Science Citation Database were not retrieved.
As a result, some potentially eligible RCTs which were incorporated into a systematic review and meta-analysis [4] performed by researchers from China are not included in this study.

Abbreviations
RCT: Randomized controlled trial; SMD: Standardized mean difference.

\section{Competing interests}

The authors declare that they have no competing interests.

\section{Authors' contributions}

XT and GMS conceived the study, participated in the design, collected the data, and drafted the manuscript. Both authors read and approved the final manuscript.

\section{Acknowledgments}

XT and G-MS contributed equally to this work. The authors would like to thank the editor and anonymous referees. This article was not supported by any financial sources.

\section{Author details}

${ }^{1}$ Graduate College, Tianjin University of Traditional Chinese Medicine, Anshan West Road, Nankai District, Tianjin 300193, China. ${ }^{2}$ Department of Nursing,

Tianjin Hospital, 406 Jiefang South Road, Hexi District, Tianjin 300211, China.

Published online: 24 November 2015

\section{References}

1. van Zanten AR, Dhaliwal R, Garrel D, Heyland DK. Enteral glutamine supplementation in critically ill patients: a systematic review and meta-analysis. Crit Care. 2015;19:294.

2. van Zanten AR, Sztark F, Kaisers UX, Zielmann S, Felbinger TW, Sablotzki AR, et al. High-protein enteral nutrition enriched with immune-modulating nutrients vs standard high-protein enteral nutrition and nosocomial infections in the ICU: a randomized clinical trial. JAMA. 2014;312:514-24.

3. Higgins JP, Green S, editors. Cochrane Handbook for Systematic Reviews of Interventions, Version 5.1.0, updated March 2011. Wiley Online Library; 2008.

4. Li MQ, Shu L, Wang XX, Wang XY, Liu ZJ, Zhao M. The impact of glutamine on clinical outcomes in critical and surgical patients: a systematic review and meta-analysis [in Chinese]. Parental Enter Nutr. 2014;21:101-5.

\footnotetext{
*Correspondence: tjyysgm@163.com

${ }^{2}$ Department of Nursing, Tianjin Hospital, 406 Jiefang South Road, Hexi District, Tianjin 300211, China

Full list of author information is available at the end of the article
}

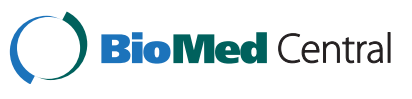

(c) 2015 Tian and Song. Open Access This article is distributed under the terms of the Creative Commons Attribution 4.0 International License (http://creativecommons.org/licenses/by/4.0/), which permits unrestricted use, distribution, and reproduction in any medium, provided you give appropriate credit to the original author(s) and the source, provide a link to the Creative Commons license, and indicate if changes were made. The Creative Commons Public Domain Dedication waiver (http://creativecommons.org/publicdomain/zero/1.0/) applies to the data made available in this article, unless otherwise stated. 